US Army Corps

of Engineers $s_{\circledast}$

Engineer Research and

Development Center

\title{
A Quantitative Risk Assessment Method for Synthetic Biology Products in the Environment
}

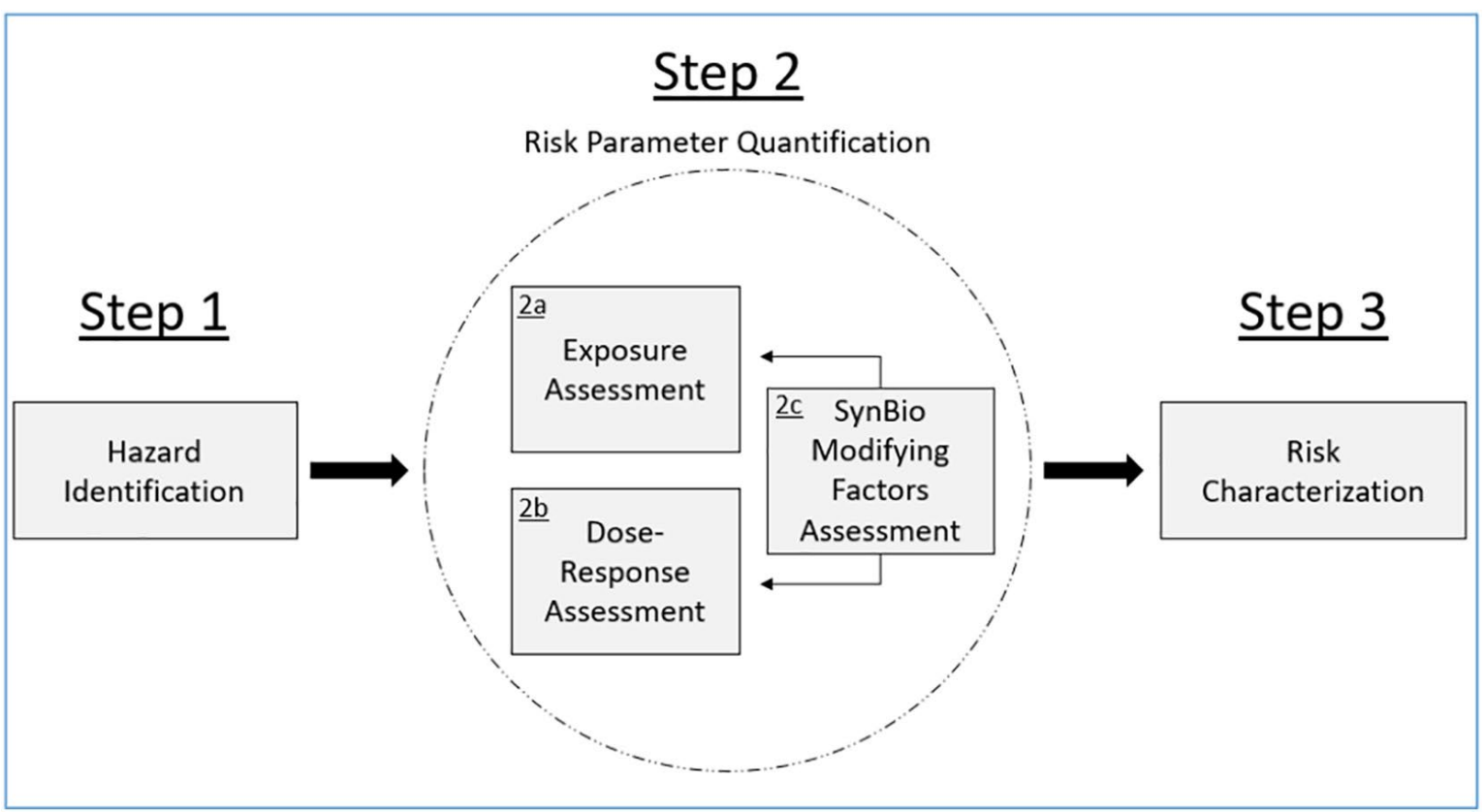


The U.S. Army Engineer Research and Development Center (ERDC) solves the nation's toughest engineering and environmental challenges. ERDC develops innovative solutions in civil and military engineering, geospatial sciences, water resources, and environmental sciences for the Army, the Department of Defense, civilian agencies, and our nation's public good. Find out more at www.erdc.usace.army.mil.

To search for other technical reports published by ERDC, visit the ERDC online library at https://erdclibrary.on.worldcat.org/discovery. 


\title{
A Quantitative Risk Assessment Method for Synthetic Biology Products in the Environment
}

\author{
Taylor Rycroft and Igor Linkov \\ Environmental Laboratory \\ U.S. Army Engineer Research and Development Center \\ 3909 Halls Ferry Road \\ Vicksburg, MS 39180 \\ Kerry Hamilton \\ School for Sustainable Engineering and the Built Environment \\ The Biodesign Institute Center for Environmental Health Engineering, \\ Arizona State University \\ Tempe, AZ 85281 \\ Charles N. Haas \\ Department of Civil, Architectural and Environmental Engineering \\ Drexel University \\ Philadelphia, PA 19104
}

Final report

Approved for public release; distribution is unlimited.

\author{
Prepared for U.S. Army Corps of Engineers \\ Washington, DC 20134 \\ Under U.S. Army Environmental Quality and Installations Research Program
}




\section{Preface}

This study was conducted for the U.S. Army Corps of Engineers and was funded in part by the U.S. Army Environmental Quality and Installations Research Program. The Technical Director was Dr. Elizabeth Ferguson.

The work was performed by the U.S. Army Engineer Research and Development Center, Environmental Laboratory (ERDC-EL). At the time of publication of this paper, the Deputy Director of ERDC-EL was Dr. Brandon Lafferty and the Director was Dr. Edmund J. Russo Jr.

This article was originally published online in Science of the Total Environment on 14 August 2019.

The Commander of ERDC was COL Teresa A. Schlosser and the Director was Dr. David W. Pittman.

DISCLAIMER: The contents of this report are not to be used for advertising, publication, or promotional purposes. Citation of trade names does not constitute an official endorsement or approval of the use of such commercial products. All product names and trademarks cited are the property of their respective owners. The findings of this report are not to be construed as an official Department of the Army position unless so designated by other authorized documents. 


\section{A quantitative risk assessment method for synthetic biology products in the environment}

\section{G R A P H ICA L A B S T R AC T}

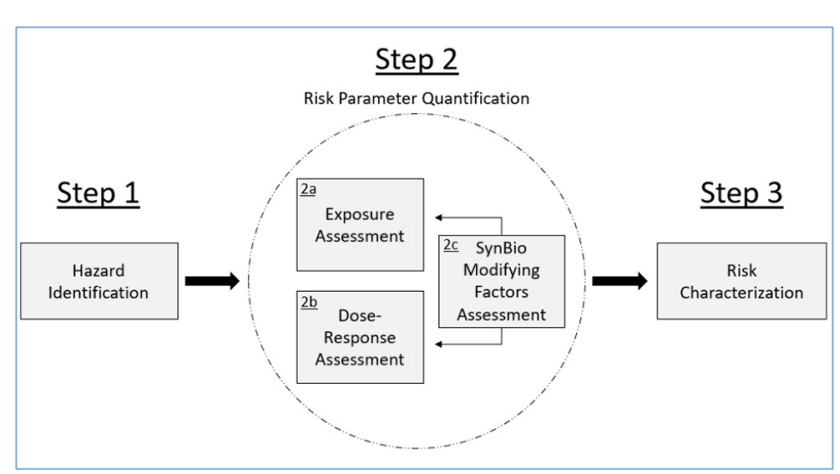

\section{A B S T R A C T}

The need to prevent possible adverse environmental health impacts resulting from synthetic biology (SynBio) products is widely acknowledged in both the SynBio risk literature and the global regulatory community. To-date, however, discussions of potential risks of SynBio products have been largely speculative, and the limited attempts to characterize the risks of SynBio products have been non-uniform and entirely qualitative. As the SynBio discipline continues to accelerate and bring forth novel, highly-engineered life forms, a standardized risk assessment framework will become critical for ensuring that the environmental risks of these products are characterized in a consistent, reliable, and objective manner that incorporates all SynBio-unique risk factors. In their current forms, established risk assessment frameworks - including those that address traditional genetically modified organisms - fall short of the features required of this standard framework. To address this gap, we propose the Quantitative Risk Assessment Method for Synthetic Biology Products (QRA-SynBio) - an incremental build on established risk assessment methodologies that supplements traditional paradigms with the SynBio risk factors that are currently absent, and necessitates quantitative analysis for more transparent and objective risk characterizations. We demonstrate through a hypothetical case study that the proposed framework facilitates defensible quantification of the environmental risks of SynBio products in both foreseeable and hypothetical use scenarios. Additionally, we show how the quantitative nature of the proposed method can promote increased experimental investigation into the true likelihood of hazard and exposure parameters and highlight the most sensitive parameters where uncertainty should be reduced, ultimately leading to more targeted SynBio risk research and yielding more precise characterizations of risk. 


\section{Introduction}

The synthetic biology (SynBio) risk literature widely acknowledges the need to prevent possible adverse environmental health impacts resulting from SynBio products (Frank et al., 2015). Commonly raised concerns include the potential for SynBio organisms to persist in the environment, become invasive, disrupt food webs, transfer genetic material via vertical gene flow or horizontal gene transfer, and impact biodiversity and ecosystems (Epstein and Vermeire, 2016). Additionally, there is apprehension that combining sequences in a new biological organism may result in an organism whose risk profile could be higher than that of the contributing organisms or sequences (Giese and von Gleich, 2015; Howard et al., 2017). Though discussions of these concerns are generally in accord, they comprise $<5 \%$ of the literature in the SynBio physical and social sciences research domains (Trump et al., 2019). Furthermore, such discussions are often speculative because the experimental data to definitively support or refute these concerns are limited (Edwards, 2014; Bates et al., 2015).

In the absence of robust empirical risk data, public interest groups have recommended applying the precautionary principle to any commercialization of SynBio products until specific biosafety mechanisms can be developed to keep pace with SynBio advances (Howard et al., 2017). Others have added that it is necessary to increase public funding of research on the ecological risks of SynBio (König et al., 2013). The outputs from additional risk research will not validate or refute the ecological concerns on their own, however - they must be synthesized into a reliable and objective characterization of risk using tools from risk assessment. This goal is confounded by the fact that traditional biosafety risk assessment tools have yet to be updated to address the significant challenges that SynBio poses to the current biosafety framework (Schmidt et al., 2009; Ahteensuu, 2017). Additionally, there is uncertainty as to which established risk assessment framework to apply to SynBio products, since traditional methods are generally deemed sufficient for legacy genetic engineering approaches but viewed as illequipped for deciding whether a new SynBio technique or application is safe for humans, animals and the environment (Schmidt et al., 2009). These obstacles prompted the European Commission (EC) to call for the standardization of risk assessments for SynBio (Howard et al., 2017).

At present, no risk assessment method exists to quantify the environmental risk of SynBio organisms. Numerous risk factors have been identified for the release of SynBio organisms to the environment, but few attempts have been made to quantify the frequency of their occurrence. Instead, environmental risk of SynBio products is typically considered qualitatively, where the probability of an adverse outcome is expressed as more or less likely than a comparative scenario (e.g., a non-modified analog) based on qualitative measures such as complexity, uncertainty, presence or absence of engineering controls, or the number of participants in the SynBio discipline (National Academies of Sciences, Engineering, and Medicine, 2017). It has been argued that
SynBio can simply leverage risk management solutions that have been established for the use of genetically modified organisms (GMOs; Breckling and Schmidt, 2015). The foremost example of a GMO risk management solution that is potentially translatable to SynBio is the EC's directive for environmental risk assessment, or "e.r.a.", which requires an assessor to provide authorities with extensive information in order to characterize the risk of deliberately released GMOs (EU Commission, 2001). However, the overall synthesis and interpretation of the information provided is qualitative and inherently subjective. The e.r.a also excludes parameters that the SynBio risk literature has highlighted as influential in characterizing the risk scenario such as effects from off-target gene edits and efficacy of intrinsic biocontainment measures. Thus, the e.r.a is only partially applicable to SynBio and may not be sufficiently transparent and objective to allay public concerns related to the environmental implications of SynBio products. Three scientific committees of the EC also examined this issue and concluded that existing risk assessment approaches for GMOs are generally applicable to SynBio, but "combining genetic parts and the emergence of new properties...will require improving existing methodologies" (SCENIHR, SCHER, and SCCS, 2015; Howard et al., 2017).

Here, we propose improving upon existing methodologies by developing a standard, quantitative risk assessment framework that accounts for all risk factors relevant to the characterization of environmental risk of SynBio products. Our proposed framework, called the Quantitative Risk Assessment Method for Synthetic Biology Products (QRA-SynBio), is an incremental build on established risk assessment methodologies (listed in Table 1) that supplements traditional paradigms with the SynBio risk factors that are currently absent. The method requires all parameters to be quantified resulting in an absolute risk characterization. While quantification may have significant uncertainty associated with it initially because quality data with a high degree of certainty are limited, we anticipate that this method will promote increased experimental investigation into the true likelihood of hazard and exposure parameters and will highlight the most sensitive parameters where uncertainty should be reduced, ultimately leading to more targeted SynBio risk research and yielding more precise characterizations of risk.

We demonstrate through a hypothetical case study that the proposed framework facilitates defensible quantification of the environmental risks of SynBio products in both foreseeable and hypothetical use scenarios. Such a tool is expected to be invaluable to regulators of SynBio products in the United States, such as the U.S. Department of Agriculture (USDA), U.S. Environmental Protection Agency (EPA), and the U.S. Food and Drug Administration (FDA). Examples of SynBio products that are produced now or that could be submitted to regulatory agencies for consideration in the near future include: gene drive engineered eukaryotic organisms (e.g., for control of infectious disease vectors such as mosquitos), engineered microorganisms (e.g., for bioremediation), engineered cell-free technologies (e.g., for advanced chemical production), and engineered viral systems (e.g., phages for elimination of pathogens from water) (Warner et al., 2019). While current regulation is

Table 1

Evaluation of applicability of established risk assessment frameworks to SynBio.

\begin{tabular}{|c|c|c|c|c|}
\hline Framework & $\begin{array}{l}\text { Does it promote a quantitative and } \\
\text { objective characterization of risk? }\end{array}$ & $\begin{array}{l}\text { Can it accommodate all SynBio } \\
\text { products as potential ecological } \\
\text { hazards? }\end{array}$ & $\begin{array}{l}\text { Can it accommodate a broad array of } \\
\text { environmental receptors and } \\
\text { endpoints? }\end{array}$ & $\begin{array}{l}\text { Does it account for all risk } \\
\text { factors applicable to } \\
\text { SynBio? }\end{array}$ \\
\hline $\begin{array}{l}\text { Human Health Risk Assessment } \\
\text { (Chemical Risk Assessment) }\end{array}$ & $\bullet$ & O & D & O \\
\hline Ecological Risk Assessment & D & O & $\bullet$ & 0 \\
\hline $\begin{array}{l}\text { Quantitative Microbial Risk } \\
\text { Assessment }\end{array}$ & $\bullet$ & D & D & O \\
\hline $\begin{array}{l}\text { Environmental Risk Assessment } \\
\text { for Genetically Modified } \\
\text { Organisms }\end{array}$ & O & $\bullet$ & $\bullet$ & D \\
\hline $\begin{array}{l}\text { Risk Assessment for Animal } \\
\text { Biotechnology }\end{array}$ & O & D & $\bullet$ & D \\
\hline
\end{tabular}

- Yes Partially $\bigcirc$ No. 
often deemed sufficient for addressing today's SynBio products (van Doren and Heyen, 2014), products in the near future are expected to be highly varied, less familiar, and use a much broader set of model organisms (National Academies of Sciences, Engineering, and Medicine, 2017). Therefore, regulators need to proactively adjust their risk assessment paradigms to think beyond the relative simplicity of GMOs to the more multifaceted and complicated discipline of SynBio. The QRASynBio method helps in this regard, moving SynBio-focused risk assessment beyond the high-level, qualitative discussions of biosafety and biosecurity to a more transparent and objective quantitative risk characterization, and taking a step toward answering the EC's call for standardization of risk assessments for SynBio.

\section{SynBio environmental risk factors}

Numerous environmental risks of SynBio products have been identified or hypothesized and discussed in the SynBio risk literature, including increased virulence and target host range (König et al., 2016), impacts to biodiversity by outcompeting native organisms or through propagation of homogeneity in the gene pool (Breckling and Schmidt, 2015), aid to detrimental organisms by serving as a host for pathogens (Epstein and Vermeire, 2016), production of toxic compounds or metabolites (König et al., 2013), and destruction of habitat, biogeochemical cycles, essential nutrient sources, or food webs (Tucker and Zilinskas, 2006). These risks ultimately stem from risk factors that may either apply to all organisms released to the environment, such as an organism's response to environmental stressors, or may be unique to SynBio products, such as an organism's response to off-target gene edits or failure of an intrinsic biocontainment mechanism.

In risk assessment, it is critical to identify the applicable risk factors for an organism because they directly impact the hazard and exposure parameters in a given release scenario. The key risk factors identified in the literature that have the potential to impact a SynBio organism are organized into three overarching categories and discussed below. It is important to emphasize that these are factors that modify the risk scenario - i.e., the 'hazard' and 'exposure' elements of the risk equation - and not factors that contribute to the genetic modification of the organism itself.

\subsection{Category 1: response to the genetic construct}

The potential for a SynBio product to cause harm to the environment is influenced by how the product responds to its genetic modification. There are several key risk factors in this category that may contribute to environmental risk, including:

\subsubsection{Expression of the genetic construct}

Direct expression of the genes encoded by the genetic construct may contribute to an increase in pathogenicity or virulence, a result demonstrated by the intentional genetic manipulation of the avian influenza virus H5N1 which increased its transmissibility in mammals (Falkow, 2012) and the unintentional increase in virulence of a mousepox virus through the addition of the interleukin- 4 gene to the viral genome (Jackson et al., 2001). Additionally, expression of certain enzymes may result in an increase in toxic metabolites that can affect habitats (König et al., 2013), or could affect quorum sensing pathways.

Fitness, or an organism's ability to survive and reproduce, may also be affected by alterations in protein expression. For example, some genetically modified bacteria have been shown to compete poorly with indigenous communities in the long run due to the extra energy demands imposed by the synthetic construct (Cases and de Lorenzo, 2005), while others have demonstrated comparable fitness to wild-type organisms (Sayler and Ripp, 2000). Similarly, multicellular organisms may experience selective advantage or disadvantage if the genetic construct alters the formation of tissues (Breckling and Schmidt, 2015).

\subsubsection{Disruption to cellular processes/integrity (interactions)}

The presence or expression of the genetic construct has the potential to disrupt essential cellular processes through perturbations to cell regulatory processes or alterations of molecular interactions. Chen et al., 2009 underscore the uncertain effects that disruptions such as gene expression and splicing have on the behavior of biological circuitry and systems which may ultimately impact the fitness of a modified organism, cautioning that synthetic devices will perturb cellular functions and that there are also likely to be both parasitic interactions between synthetic components of the cell as well as unpredictable interactions with natural elements of the host (Chen et al., 2009). Similarly, Breckling and Schmidt warn that the interaction potential of the molecular entities should not be downplayed, emphasizing that it is naïve to believe that it is possible to add a genetic construct to a cell without affecting its integrity in a significant way. The authors point out that it is important to identify any disruptions which could become the potential starting point of a cause-effect chain which gives rise to undesirable or harmful results (Breckling and Schmidt, 2015).

\subsubsection{Mutation (stability)}

The presence or expression of the synthetic construct may impact genetic stability and ultimately affect the rate of divergence from the wild-type organism. SynBio products may undergo undirected mutations and recombination as a result of inherent mutation rates of the host organism or chassis, response to environmental stressors in the ecosphere (Breckling and Schmidt, 2015), or induced mutation from gene editing that results in internal stress from the foreign construct and subsequent attempts to reject the modification (Dan-Cohen, 2016). Pósfai et al. emphasize that even in a well-characterized microbiological chassis like E. coli, synthetic constructs are not always tolerated, and mutagenesis serves as the organism's defense against expression of products that are deleterious. Specific genes and plasmids have shown to be very unstable when propagated in standard $E$. coli hosts as a result of DNA elements like insertion sequence elements, transposases, defective phages, integrases, and site-specific recombinases that are disseminated throughout the genome (Pósfai et al., 2006). The phenotypic outcomes of these possible mutations must also be considered, as undesirable consequences related to fitness, transport, virulence and other hazard and exposure parameters have been raised for SynBio plants (Birchler, 2015), animals (FDA, 2015; FDA, 2016), and microorganisms like bacteria and viruses (König et al., 2013).

\subsubsection{Gene transfer/flow}

A SynBio product may respond to its genetic modification by altering its tendency to pass genetic information to other organisms, either through horizontal gene transfer (HGT) or vertical gene flow. HGT is a behavior commonly exhibited by prokaryotes as a mechanism to acquire new traits and ensure resilience in the face of environmental change (McDaniel et al., 2010). Studies have found that $81 \%$ of genes in an average bacterial genome and $60 \%$ of genes in cyanobacteria have been affected by HGT at some point in their history (Dagan et al., 2008; Dagan et al., 2012). Through conjugation, transformation, transduction, and the use of gene transfer agents (GTAs), bacteria and archaea rapidly gain and lose certain genes (Zamani-Dahaj et al., 2016). HGT also occurs in eukaryotic species, although this form of heritable exchange is believed to occur at much lower frequencies than is observed in prokaryotes (Schwartz et al., 2014; Crisp et al., 2015). In some modified marine bacteria, GTA-mediated gene transfer frequencies have been shown to range from $6.7 \times 10^{-3}$ to $4.7 \times 10^{-1}$ (unitless) under ecologically relevant conditions, values a thousand to a hundred million times higher than prior estimates of HGT in the oceans (McDaniel et al., 2010). Other transfer frequencies have been shown to range from $10^{-6}$ to $10^{-3}$ for modified plasmids transferred via conjugation from introduced bacteria to indigenous organisms in a bioremediation scenario (Neilson et al., 1994). 
The rate at which SynBio organisms transfer synthetic constructs to indigenous organisms can also be influenced by the amount and activity of promiscuous plasmids and mobile genetic elements (Cases and de Lorenzo, 2005). Additionally, SynBio organisms do not necessarily need to be living in order for their DNA to be available to indigenous organisms. Post-mortem, the cell-free synthetic DNA can persist in the environment and remain functional and passively transferable even after exposure to harsh conditions (Moe-Behrens et al., 2013; Schmidt and Pei, 2015).

HGT typically occurs when a prokaryote achieves the physiological state of competence, which is associated with the organism's stationary phase and often induced by stressors such as high cell density, waste buildup, or nutrient limitation. A key concern is that when released to the environment, a SynBio organism is likely to face stressful conditions and therefore more likely to become competent and exchange genetic material with the surrounding community in an effort to adapt (Vos et al., 2015). This genetic exchange could potentially impact either the SynBio organism or the indigenous organism's development, behavior, or pathogenicity depending on which organism is the recipient of the impactful genetic material (König et al., 2013). For example, researchers have demonstrated the ability to confer pathogenic properties upon laboratory strains of $E$. coli through the experimental introduction of genes from other species (Ochman et al., 2000). The spread of virulence or resistance factors in an uncontained environment could adversely affect susceptible species through changes in population disease dynamics. Additional concerns related to HGT include the potential for SynBio organisms to transfer intrinsic biocontainment mechanisms (e.g., kill switches) to indigenous species and trigger die-offs, or to affect the biodiversity of the ecosystem by driving genetic homogeneity or conferring selective advantages to a small subset of species (Vos et al., 2015).

In vertical gene flow, a parent organism passes genetic material to its offspring. For SynBio organisms, a primary concern is that the implications of the synthetic modification may not become evident directly and immediately after the transformation event in the laboratory, but rather may be forwarded through inheritance and amplified autocatalytically in the course of subsequent generations where it causes effects in new and unforeseen contexts (Breckling and Schmidt, 2015).

\subsubsection{Intrinsic biocontainment}

The presence of intrinsic biocontainment mechanisms such as engineered kill switches, auxotrophic dependence, and incorporation of xeno-nucleic acids (XNA) - and the efficacy and failure rate of these controls - will significantly impact a SynBio organism's ability to persist in the environment. The principle aims of intrinsic biocontainment are to (1) control growth of the SynBio organism in the research laboratory or after an unintentional environmental release, and (2) prevent HGT from a SynBio organism to a natural one (Howard et al., 2017). Controlled cell growth is typically addressed using either (i) engineered auxotrophy, which renders the organism dependent on a particular compound that is essential for its growth but that it is incapable of synthesizing on its own or accessing outside of the controlled environment, or (ii) genetic safeguards like kill switches and vector suicide strategies that restrict or terminate the organism's viability in defined environments (Chan et al., 2016). Biocontainment to prevent HGT is largely theoretical at this time, but "semantic firewalls" have been proposed in which SynBio organisms possess chromosomes made from nonnatural nucleic polymers called XNA rather than traditional DNA and RNA, such that they cannot be read or duplicated by indigenous organisms that possess only natural DNA and RNA polymerases (König et al., 2013). Other strategies include use of unnatural amino acids or codon reassignment (Schmidt and Pei, 2015; Torres et al., 2016).

Reviews of intrinsic biocontainment strategies point out that while many engineered safety locks show promise, there is no single reliable safeguard technology at present (Epstein and Vermeire, 2016). Spontaneous mutations and positive selection pressures enable SynBio organisms to 'escape' fail-safe mechanisms by destroying the genetic switch or bestowing immunity against a lethal gene, thereby allowing the organisms to propagate outside of their contained environment (Ahteensuu, 2017; Moe-Behrens et al., 2013). Chan et al. noted such events in a stability study of their 'Deadman' and 'Passcode' kill switch circuits which showed reduced killing efficiency over time as they were short-circuited or inactivated by mutations (Chan et al., 2016). The National Institutes of Health $(\mathrm{NIH})$ recommends that escape rates not exceed a threshold frequency of $10^{-8}$ (i.e. one cell per $10^{8}$ cells; $\mathrm{NIH}, 2016$ ), however few independent genetic safeguards meet this limit, and these limits may also be challenging to demonstrate, depending on the detection limit of the assay used. In a review by Moe-Behrens et al., fourteen published escape rates were identified ranging from $10^{-9}$ to $10^{-4}$ (for systems tested under laboratory conditions and in environmental microcosm models), four of which (29\%) met or surpassed the $10^{-8}$ threshold (Moe-Behrens et al., 2013).

Intrinsic biocontainment methods are rapidly improving, however, and redundant safeguards and combinations of two or more safeguards linked in an independent manner have shown promise of escape frequencies lower than those demonstrated by stand-alone mechanisms. Cai et al. demonstrated an escape frequency of $<10^{-10}$ when two mechanisms were independently combined compared to the $<10^{-6}$ frequency provided by each mechanism individually, and Gallagher et al. demonstrated overlapping safeguards that limit escape frequencies to $<1.3 \times 10^{-12}$ (Cai et al., 2015; Gallagher et al., 2015). Additionally, an unnatural amino acid biocontainment mechanism has shown escape frequencies that reached $<4.4 \times 10^{-11}$ (Ravikumar and Liu, 2015).

\subsection{Category 2: response to the gene editing process}

The potential for a SynBio product to cause harm to the environment is also influenced by how the product will respond to the gene editing technique used and how this response will modify hazard and exposure parameters. Unintended alterations made to the genome, called 'off-target' gene edits, are the key risk factors in this category that may contribute to environmental risk:

\subsubsection{Off-target gene edits}

Off-target gene edits may impact an organism's integrity similar to a mutation event. Accidental activation or disabling of genes, disruption of critical pathways, facilitation of translocation events, and removal of nonessential genes can all affect genomic stability and ultimately impact an organism's ability to cause harm in the environment. The frequency of off-target events depends in part on the gene editing tool employed, where the three most commonly tools cited in the SynBio literature are zinc finger nucleases (ZFNs), transcription activator-like effector nucleases (TALENs), and RNA-guided nucleases like the CRISPR/ cas systems (Fu et al., 2013).

CRISPR/Cas9 is widely touted as the most precise of the genomeediting technologies, exhibiting a high specificity and inducement of only several - rather than thousands - of off-target mutations in an entire genome (Hruscha et al., 2013; Kim et al., 2015). However, Zhang et al. point out that even CRISPR/Cas9 can have a high frequency of off-target activity ( $\geq 50 \%$ ) and that in some instances off-target cleavage can occur on DNA sequences with up to three to five base pair mismatches with a portion of the RNA-guide sequence (Zhang et al., 2015). Fu et al. corroborate these findings, noting that single and double mismatches are tolerated to varying degrees depending on their position along the guide RNA-DNA interface, and that off-target edits can occur at sites harboring up to five mismatches from the intended ontarget site (Fu et al., 2013).

\subsection{Category 3: response to environmental stressors}

The potential for any organism, including SynBio products, to cause harm to the environment is heavily influenced by how the product will respond to environmental conditions in the specific release 
scenario. Thus, the key risk factor in this category that may modify hazard and exposure parameters and ultimately contribute to environmental risk is not SynBio-unique, but must be accounted for in any SynBio risk assessment:

\subsubsection{Environmental stress-response}

Conditions of the receiving environment relative to the SynBio organism's development conditions, including nutrient availability, temperature, humidity, $\mathrm{pH}$, competition, biological community, predation, and other biotic and abiotic factors can elicit complex changes in the organism's ability to grow, allocate energy, perform essential functions, or regulate gene activity (Cases and de Lorenzo, 2005). Breckling and Schmidt point out that genes can change their activity and even the gene products of a given set of genes can differ depending on variations in the surrounding ecological context. Additionally, biotic and abiotic stressors may have a different effect when interfering with a SynBio organism, as compared to the conventional complement (Breckling and Schmidt, 2015). Environmental stressors can also impact mutation rate and rate of HGT, as mutation rate is in part determined by the fidelity of the replication and repair machinery of the cell and can be elevated directly by extrinsic stress factors, and HGT is in part determined by the genetic regulation of competence (Vos et al., 2015).

To-date, the above-mentioned risk factors for a SynBio organism are generally understood and acknowledged in the literature, but are primarily discussed in a qualitative manner. We are unaware of any published efforts to quantify the impacts of these risk factors and incorporate them into an objective risk characterization for a SynBio product. This may be partially due to the fact that there is no standard framework for performing a quantitative risk assessment for SynBio products. Such a framework would not only help establish a more robust and transparent characterization of risk than current qualitative methods afford, but would also serve as a placeholder that illustrates for researchers where data gaps lie, thereby encouraging the performance of laboratory studies to close those gaps with quantitative data. Existing risk assessment paradigms can provide a valuable foundation for developing a quantitative risk assessment methodology for SynBio products without starting anew, but they must be adapted to address risk factors relevant to SynBio products.

\section{Existing risk assessment paradigms and their applicability to SynBio}

We examined five established, biologically-relevant risk assessment frameworks (Table 1) for their applicability to environmental risk assessment for SynBio products and found that no single framework is suitable on its own for standardization and inclusion of all SynBio products. A single, standardized framework is feasible, but existing risk assessment paradigms require modification to achieve this objective.

The ideal standard framework should meet four essential criteria: (1) it must be quantitative to ensure greater objectivity and transparency, (2) it must be able to accommodate all SynBio products as potential ecological hazards, (3) it must be able to accommodate a broad array of environmental receptors and endpoints, and (4) it must account for all of the aforementioned environmental risk factors applicable to SynBio. Evaluation of the applicability of the five risk assessment frameworks to SynBio is depicted in Table 1. Frameworks received 'Yes,' 'Partially,' and 'No' designations denoting their ability to address the four essential criteria.

\subsection{Human health risk assessment (chemical risk assessment)}

EPA defines Human Health Risk Assessment (HHRA) as "the process to estimate the nature and probability of adverse health effects in humans who may be exposed to chemicals in contaminated environmental media, now or in the future" (U.S. EPA, 2018). The HHRA methodology is divided into four steps: Hazard Identification, Dose-Response
Assessment, Exposure Assessment, and Risk Characterization (NRC, 1983). The Risk Characterization is the final step that integrates qualitative information, quantitative information, and information about uncertainties from the preceding three steps into an estimate of the likelihood of an adverse human health outcome (Fowle and Dearfield, 2000). This risk estimate is typically quantitative, particularly when used to inform chemical policy decisions. Traditionally, the sole 'receptor' in HHRA is a human or human population; however, the chemical risk assessment method can be extrapolated to ecological receptors in both the eukaryotic and prokaryotic domains. Additionally, chemicals and radiation are the only hazardous entities considered in HHRA; there is no consideration of biological hazards and therefore no consideration of SynBio risk factors.

\subsection{Ecological Risk Assessment (ERA)}

In its Framework for Ecological Risk Assessment, EPA sets forth risk assessment guidelines for evaluating the adverse effects of stressors on ecosystems and components of ecosystems (Norton et al., 1992). EPA notes that the framework is conceptually similar to the approach used for HHRA, but highlights the following three key areas of distinction:

1) ERA can consider effects beyond those on individuals of a single species and may examine a population, community, or ecosystem.

2) There is no single set of ecological values to be protected; values are selected from a number of possibilities based on both scientific and policy considerations.

3) ERA considers nonchemical as well as chemical stressors.

Additionally, in ERA, the Hazard Identification and Dose-response Assessment are combined in an 'Ecological Effects Assessment' phase, and the term "Dose-response" is replaced by "stressor-response" to account for nonchemical stressors that may not be measured in doses. The final characterization of risk can be expressed as a qualitative or quantitative estimate depending on available data, however EPA notes that in most instances, the likelihood of an adverse environmental outcome is expressed in a qualitative statement (Norton et al., 1992).

The ERA framework is intended to be flexible while providing a logical and scientific structure to accommodate a broad array of stressors (i.e., chemical and nonchemical). EPA specifies, however, that the framework focuses exclusively on physical and chemical stressors and that discussion of "accidentally or deliberately introduced species, genetically engineered organisms, or organisms used to control horticultural or agricultural pests" is intentionally excluded. The ERA framework has the underpinnings to accommodate all SynBio products as potential ecological stressors but purposefully omits this class of environmental hazards by not considering the capacity of these products to reproduce and interact with the natural environment. Accordingly, there is no consideration of SynBio risk factors in ERA.

\subsection{Quantitative Microbial Risk Assessment (QMRA)}

Quantitative Microbial Risk Assessment (QMRA) is used to estimate the risk of adverse health consequences resulting from exposure to a pathogen (Haas et al., 2014). The QMRA framework is structurally identical in framework to HHRA, however the hazard, exposure, doseresponse, and risk characterization steps are focused on microorganisms rather than chemicals, and each step accounts for the properties of living organisms (CAMRA, 2018).

The QMRA dose-response assessment utilizes various functional forms (such as the exponential or Beta-Poisson model) to describe the probability of infection or illness from a given dose of pathogens based on a quantal response of, typically, vertebrate animals exposed to various doses of a pathogen during experimental trials (Haas, 2015). This approach differs from HHRA carcinogen/non-carcinogen approaches for dose-response modeling that make use of uncertainty factors and 
other extrapolation approaches for low doses that are difficult to observe under experimental conditions (Haas et al., 2014). Additionally, QMRA does not normalize microbial doses per unit receptor bodyweight.

While QMRA has not been formally applied for assessment of SynBio risks, it has been used to compare the risk from various strains of the same bacteria such as Mycobacterium avium. This demonstrates its utility in developing independent dose-response models for the same bacteria, and/or applying modifying factors for existing dose-response models to extrapolate among disparate microbial strains, exposure routes, sub-populations, or other characteristics of interest in a risk assessment where exact chassis information is not available (Hamilton et al., 2017).

The concluding risk characterization is intended to be quantitative in QMRA and is expressed as a probability of a given health endpoint occurring in the population at risk.

Traditionally, the sole 'receptor' in a QMRA is a human or human population, however the microbial risk assessment method could presumably be extrapolated to ecological receptors in both the eukaryotic and prokaryotic taxa. For example, the dose-response data upon which the original Beta-Poisson dose-response model was derived is for the tobacco mosaic virus in plants (Furumoto and Mickey, 1967a; Furumoto and Mickey, 1967b; Haas, 1996). Furthermore, "third generation" and beyond approaches have been proposed to account for intermediate molecular events that could be combined with a "key events dose-response framework," as well as other approaches to more granularly address the interaction of microorganisms with host physiological systems and to couple dose-response with dynamic disease transmission models that could serve to better characterize downstream SynBio impacts compared to earlier static approaches (Haas, 2015).

Microorganisms are generally the only hazardous entities considered in a QMRA; there is no consideration of multicellular biological hazards. However, applying this approach to multicellular taxa such as fungi and algae has been recommended (Haas, 2015). Others have suggested that meta-omics data could be incorporated into microbial risk assessments either to prioritize targets or model the impacts of the microbial community on the risk scenario (Cocolin et al., 2018). These authors are unaware of studies that apply QMRA to genetically modified microorganisms or that incorporate SynBio risk factors into the risk assessment.

\subsection{Environmental risk assessment genetically modified organisms (e.r.a)}

The European Parliament and the Council of the European Union adopted directive 2001/18/EC in 2001, which outlines provisions for the deliberate release of genetically modified organisms (GMOs) into the environment (EU Commission, 2001). In Annex II, the directive outlines principles for an environmental risk assessment (e.r.a) which is intended to "identify and evaluate potential adverse effects of the GMO, either direct and indirect, immediate or delayed, on human health and the environment which the deliberate release or the placing on the market of GMOs may have." The 'receptors' in the e.r.a. include all ecological endpoints ranging from individual organisms to populations and communities. The e.r.a. also considers any genetically modified organism that may pose an environmental hazard including single- and multicellular organisms. The six steps in the e.r.a. are:

1) Identification of characteristics which may cause adverse effects

2) Evaluation of the potential consequences of each adverse effect, if it occurs

3) Evaluation of the likelihood of the occurrence of each identified potential adverse effect

4) Estimation of the risk posed by each identified characteristic of the $\mathrm{GMO}(\mathrm{s})$

5) Application of management strategies for risks from the deliberate release or marketing of $\mathrm{GMO}(\mathrm{s})$

\section{6) Determination of the overall risk of the $\mathrm{GMO}(\mathrm{s})$}

Within these six steps, the directive prompts the assessor to qualitatively consider several SynBio risk factors including the synthetic construct's effects on gene transfer, phenotypic and genetic instability (i.e. mutation), virulence and toxicity factors, and the relative magnitude of these alterations compared to a non-modified analog under corresponding conditions of the release or use. The characterization of risk in Step 4 is estimated by combining the likelihood of the adverse effect occurring and the magnitude of the consequences if it occurs; the parameters and the concluding risk characterization are represented qualitatively.

In Annex III, the directive outlines the information required in the notification to the national competent authority. Extensive information is collected pertaining to the GMO, conditions of release, the receiving environment, and interactions between the GMO and the environment. Much of this information is inherently quantitative (e.g., generation time, median infective dose, level of expression of the construct, etc.), however, this quantitative data is not required to be used to form a quantitative characterization of risk in the e.r.a. described in Annex II.

\subsection{Risk assessment for animal biotechnology}

In its report Animal Biotechnology: Science-Based Concerns, the National Research Council (NRC) of the National Academies presents findings of human and environmental risk issues stemming from products of animal biotechnology (National Research Council, 2002). The report describes animal biotechnology implications for food safety, the environment, and animal health and welfare. The NRC committee cautions that "potential impacts on the environment from the escape or release of genetically engineered organisms was the committee's greatest science-based concerns associated with animal biotechnology." The environmental concerns focus primarily on risks of transgene spread through vertical gene transmission followed by natural selection, with some discussion of horizontal gene transfer.

While the committee states that the traditional four-step risk assessment structure of hazard identification, exposure assessment, doseresponse assessment, and risk characterization do not apply well to genetically engineered (GE) organisms in the environment, it goes on to outline its risk analysis process in five analogous steps:

1) to identify the potential harms regardless of likelihood,

2) to identify the potential hazards that might produce those harms,

3) to define what exposure means for a GE organism and the likelihood of exposure,

4) to quantify the likelihood of harm given that exposure has occurred, and

5) to multiply the resulting probabilities to prioritize risk.

The output of the committee's overall assessment of environmental concern is a risk ranking of GE animals according to 'level of concern,' where level of concern is determined through a product of the variables "fitness of the GE organism," "ability to escape and disperse," and "stability of the receiving environment." The resulting product is scaled qualitatively, ranging from low to high. In evaluating these variables, the committee accounts for several SynBio risk factors, including how a transgenic construct leads to production of novel products, how it influences mega-mutations that instantaneously and substantially change the phenotype of the organism, and how it enhances existing traits like growth rate, the ability to adapt to a wider range of environmental conditions, and the ability to spread. Importantly, the committee describes the importance of understanding the magnitude to which the engineered construct modifies these factors relative to wild-type comparators.

The 'receptors' in the NRC report include all ecological endpoints ranging from individual organisms to populations and communities. 
GE animals are the only hazardous entities considered; there is no consideration of engineered microbial or plant hazards.

\section{Proposed framework: Quantitative Risk Assessment for Synthetic Biology Products (QRA-SynBio)}

The five established risk assessment frameworks examined above are partially applicable to SynBio, but none can function independently as a standardized framework for the quantitative risk assessment for SynBio products. To achieve this end, we propose an incremental build on these paradigms, leveraging the components that enable fulfillment of the four essential criteria and account for all SynBio risk factors. The model we propose, called the Quantitative Risk Assessment Method for Synthetic Biology Products (QRA-SynBio), utilizes the Hazard Identification, Exposure Assessment, Dose-Response Assessment, and Risk Characterization steps common to several of the established risk assessment paradigms. The key addition to these steps is the SynBio Modifying Factors Assessment (Fig. 1). Each step of the method is described below.

\subsection{Step 1: hazard identification}

The objective of the Hazard Identification step in the QRA-SynBio method is to identify the SynBio organism and the spectrum of adverse environmental health outcomes associated with it. Proper identification of the SynBio organism requires an understanding of its closest comparators, host chassis organism, donor organism, SynBio construct form and function, and suitable surrogates and proxies for hazard and exposure data. Identification of the adverse environmental health outcomes first requires an inventory of all environmental receptors that may be impacted by the SynBio product. Potential effects on all levels of biotic and social organization must be considered (Breckling and Schmidt, 2015). Next, adverse health outcomes must be identified which may result from exposure to either direct or indirect hazard mechanisms. Direct hazard mechanisms are those that result from direct exposure to the SynBio product and are more likely to be immediate (e.g., infectivity/ virulence, production of toxic chemicals, gain or loss of function of specific genes, etc.). Indirect hazard mechanisms are those that result from indirect interaction with the SynBio product and are more likely to be delayed (e.g., impacts to biodiversity, destruction of habitat or essential nutrient sources, aid to detrimental organisms, etc.) (EU Commission, 2001). Lastly, the Hazard identification step requires the risk assessor to prioritize the possible environmental receptor and adverse health outcome combinations and select a single combination for which risk will be calculated. There are likely to be multiple environmental receptor and adverse health outcome combinations, but only one can be selected at a time for quantitative risk assessment. However, many combinations will utilize the same or very similar hazard and exposure parameters which can be leveraged in subsequent risk assessments for other environmental receptor and adverse health outcome combinations.

If there is limited hazard data for the SynBio product, empirical tests must be performed for potential adverse environmental health outcomes or assumptions must be made using surrogates and proxies. If it is unclear whether the SynBio product behaves like a comparator or surrogate, benchmarking tests must be performed to establish the relative behavior of the synthetic organism compared to the surrogate. Natural comparators, host chassis organisms, and donor organisms may not always be available, as part of SynBio is concerned with new kinds of biological systems and pre-life forms (Ahteensuu, 2017; EU Commission (EC), 2015). In such cases, empirical tests must be performed for potential adverse environmental health outcomes, shifting the risk assessment from a more prediction-based assessment to more empirical testing (König et al., 2013).

\subsection{Step 2: risk parameter quantification}

Step 2 of the QRA-SynBio method consists of three sub-steps which focus on the identification and quantification of the risk parameters through: a) Exposure Assessment, b) Dose-response Assessment, and c) SynBio Modifying Factors Assessment.

\subsubsection{Step 2a: exposure assessment}

The objective of the Exposure Assessment step in the QRA-SynBio method is to determine the extent of a receptor's exposure in terms of number of SynBio organisms encountered. First, the assessor must define the scenario of interest and the point of exposure (in space and time) at which the environmental receptor is exposed to the SynBio product. The assessor must also determine whether the intended use of the SynBio product requires containment, and describe the degree of containment. Next, the assessor must list the exposure parameters, or all of the factors that contribute to the number of SynBio organisms to which the environmental receptor is exposed. These may include

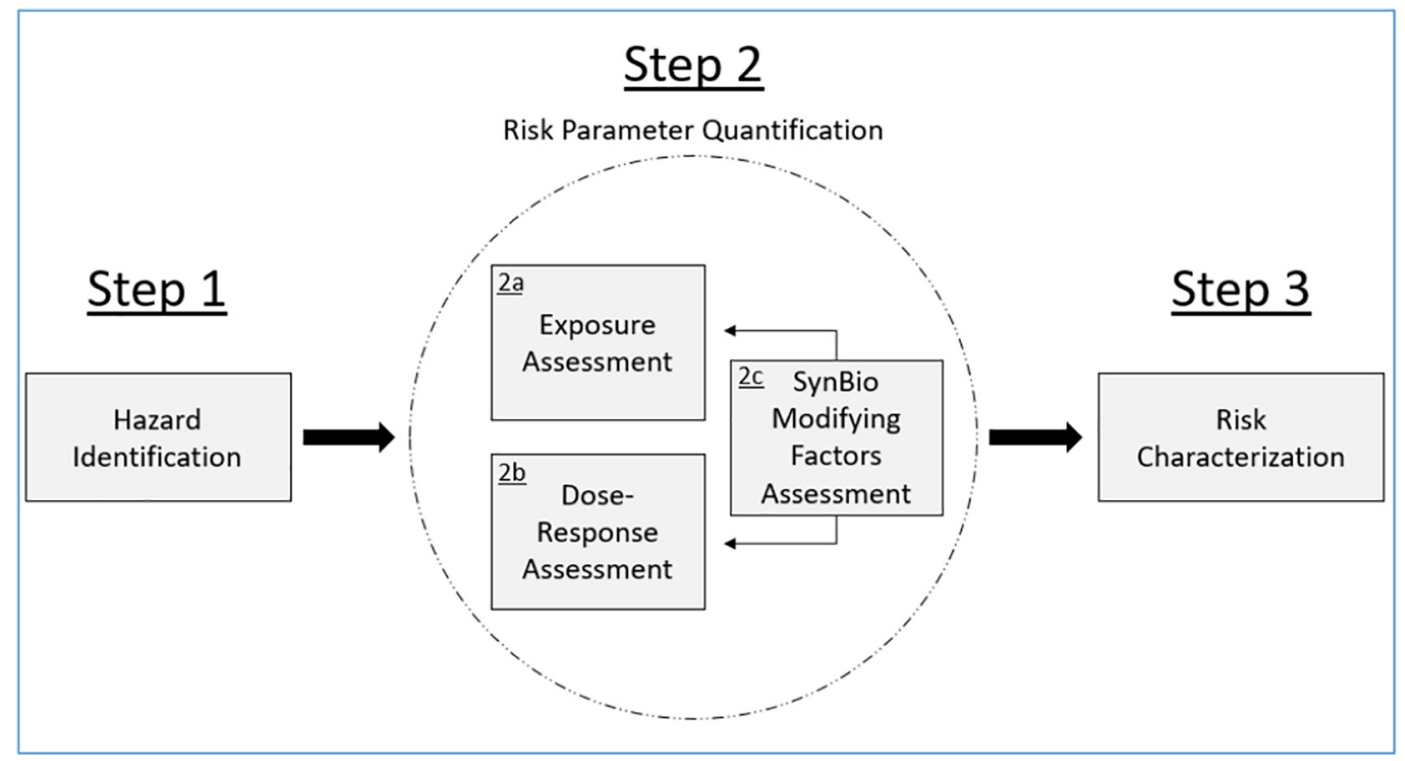

Fig. 1. Quantitative Risk Assessment Method for Synthetic Biology Products.

(Adapted from Trump et al., 2018.) 
extrinsic or intrinsic biocontainment, initial dose, growth rate and dieoff rate, mutation rate, rate of gene transfer, heritability of the synthetic genotype, environmental travel time, partition effects, organism mobility, encounter or intake rate of environmental receptor, transmissivity, change in receptor genetic function (an intermediate health endpoint), and receptor survival, activity, and competitiveness (an intermediate health endpoint).

To establish a quantitative characterization of risk, the exposure parameters must be translated into an equation for dose, which quantifies the number of SynBio organisms, intact genetic constructs, or active amount of protein or nucleic acids encountered. Where possible, each exposure parameter should be represented by a distribution rather than a point value to represent variability and uncertainty, and a Monte Carlo simulation should be carried out to determine the likely range of potential exposure doses.

\subsubsection{Step 2b: dose-response assessment}

The objective of the Dose-response Assessment step in the QRASynBio method is to characterize the relationship between the number of SynBio organisms encountered and the occurrence of the adverse environmental health outcome which includes undesirable phenotypes. This step requires dose-response curve-fitting of real or surrogate data from the SynBio organism and the environmental receptor and subsequent determination of the best-fit dose-response equation. In determining the best-fit dose-response equation, it is important to note whether the endpoint effect requires multiplication in the host, in which case a traditional dose-response function from QMRA may be applicable (e.g., beta-poisson, exponential, etc.). If the endpoint effect does not require multiplication in the host then a dose-response function from chemical risk assessment may be appropriate. Uncertainty must also be characterized for the dose-response curve and the best-fit equation parameters.

\subsubsection{Step 2c: SynBio modifying factors assessment}

The objective of the SynBio Modifying Factors Assessment step in the QRA-SynBio method is to identify the risk factors that impact a SynBio organism's hazard and exposure parameters in the scenario of interest and quantify their impact (Fig. 2). These factors include the elements from Categories 1-3 described earlier: response to the genetic construct, response to the gene editing process, and response to environmental stressors. As mentioned previously, these risk factors pertain to modification of the risk scenario, not the organism.

When quantifying the SynBio organism's response to the genetic construct, a risk assessor must consider how the effects of expression of the genetic construct, disruption to cellular processes and integrity (i.e., internal interactions), mutation and stability, horizontal gene transfer and vertical gene flow, and intrinsic biocontainment modify the hazard and exposure parameters. Similarly, when quantifying the SynBio organism's response to the gene editing process or to environmental stressors, a risk assessor must consider how off-target gene edits and environmental stress-response modify the hazard and exposure parameters, respectively.

\subsection{Step 3: risk characterization}

The objective of the Risk Characterization step in the QRA-SynBio method is to estimate the magnitude, variability, and uncertainty of the risk of the adverse environmental health outcome in the exposed area. This step requires calculating the probability of an adverse health outcome using outputs from the Exposure Assessment (dose) and Dose-response Assessment (best-fit dose-response equation and parameters). Uncertainty associated with the risk characterization (quartile range, etc.) must be presented and a sensitivity analysis should be performed to determine which parameters have the greatest impact on the variability of the risk characterization. All assumptions made during the risk assessment (e.g., real data vs. surrogate data, environmental conditions, etc.) must be presented and discussed.

In a risk assessment for a SynBio product, the risk assessor will face one of two conditions pertaining to knowledge of the product; they will either (1) have perfect information about the stressor and its adverse outcomes, or (2) have imperfect information and must utilize surrogate or proxy data. In the first scenario, the risk assessor may use established frameworks such as QMRA or ERA because the SynBio Modifying Factors Assessment will not be necessary; these factors are already accounted for in the empirical measurements for the hazard and exposure parameters. In the second scenario, which is the more likely scenario in the near-term, the risk assessor must modify - either increase or decrease - the risk parameters to more accurately characterize

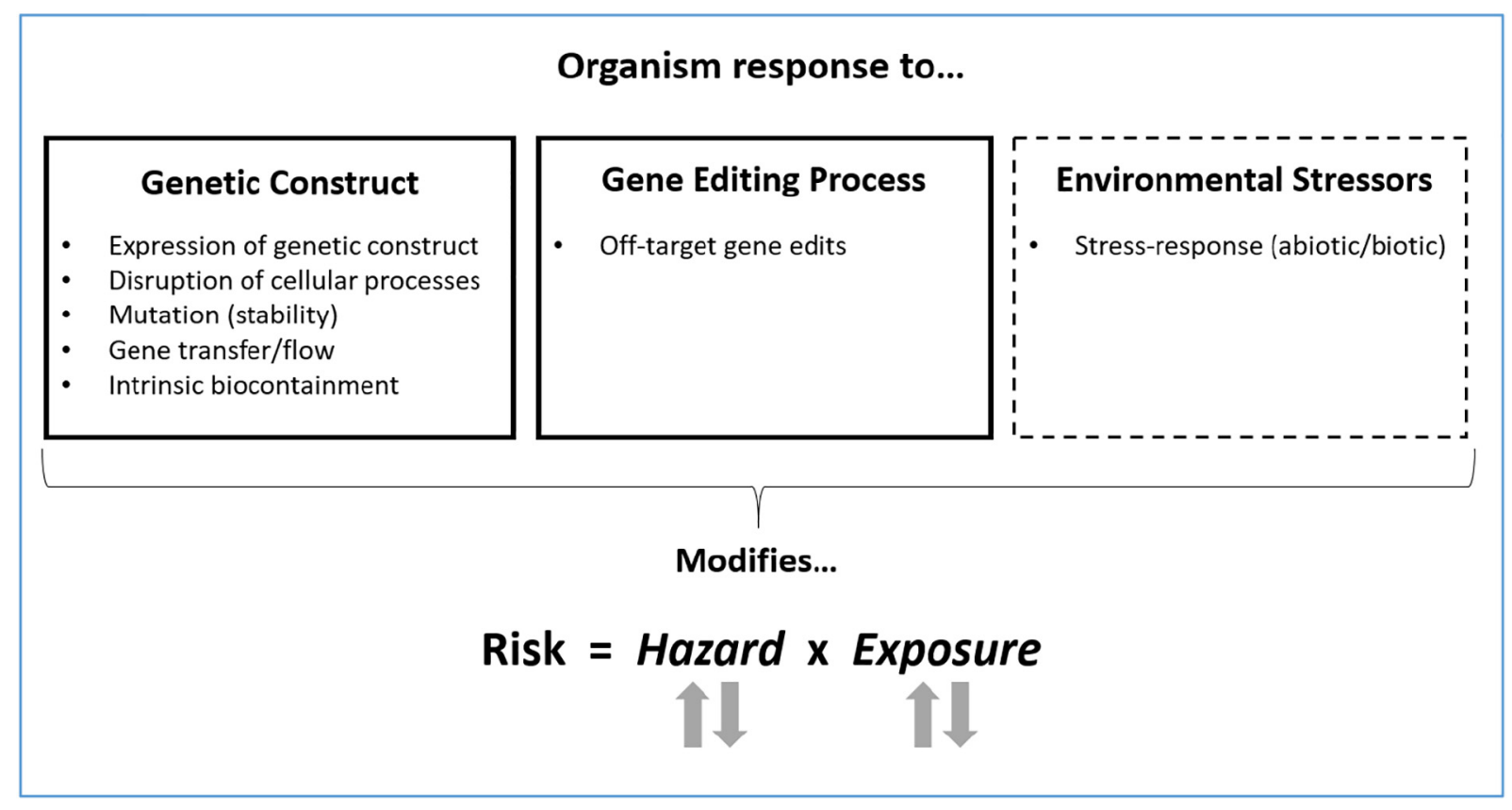

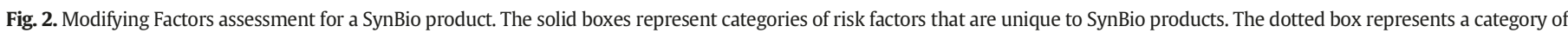
risk factors that applies to all organisms released to the environment, including SynBio products. 
Table 2

Mock data for Step 1: hazard identification.

\begin{tabular}{lll}
\hline $\begin{array}{l}\text { Hazard mechanism } \\
\text { type }\end{array}$ & Hazard mechanism & Receptor/Outcome \\
\hline Direct & $\begin{array}{l}\text { Infectivity/Virulence } \\
\text { Production of toxic chemicals }\end{array}$ & $\begin{array}{l}\text { Rainbow trout/mortality } \\
\text { No evidence }\end{array}$ \\
Indirect & $\begin{array}{l}\text { No evidence } \\
\text { Destruction of habitat or } \\
\text { nutrient source }\end{array}$ & No evidence \\
& Aid to detrimental organisms & $\begin{array}{l}\text { Soil bacteria community, } \\
\text { infection by phage/die-off }\end{array}$ \\
& &
\end{tabular}

risk; this modification is inherently relative, comparing the SynBio organism to the selected surrogate.

\section{Hypothetical case study}

The following hypothetical case uses mock data to demonstrate how the QRA-SynBio method (Fig. 1) can be applied to a SynBio product. In this case, the hypothetical SynBio product is an engineered Pseudomonas putida S-313 (P. putida S-313) soil bacterium that has been genetically modified to contain a synthetic genetic construct that codes for multiple enzymes that can perform a step-wise conversion of the perfluorinated chemical 6:2 fluorotelomer sulfonate (6:2 FTS) into benign degradation products. In the scenario of interest, the SynBio product will be used in ex situ bioremediation of contaminated soil that has been excavated and transported to a nearby treatment facility. The decontaminated soil is sterilized and returned to the excavation site where the environmental exposure occurs.

\subsection{Step 1: hazard identification}

The first step in the QRA-SynBio method is Hazard Identification, which seeks to identify the SynBio organism and the spectrum of adverse environmental health outcomes associated with it. The SynBio product in this case is P. putida S-313 and, in evaluating the closest comparator, host chassis, and donor construct, the risk assessor for this case concludes that related wild-type Psuedomonas sp. can serve as reasonably representative surrogates for the SynBio product when necessary. In this hypothetical case, the risk assessor has limited empirical hazard or exposure data for the SynBio product and will rely on surrogate data to fill knowledge gaps.

The assessor considers the potential adverse environmental health outcomes resulting from exposure to the SynBio product and generates a list of potential environmental receptors and associated adverse health outcomes in the scenario of interest. The assessor identifies that wild-type $P$. putida $S-313$ is known to infect Rainbow Trout
(Oncorhynchus mykiss), leading to mortality (Altinok et al., 2006), and concludes that this is likely to be the most significant environmental receptor and adverse health outcome combination at the affected site (Table 2). The assessor chooses "Rainbow Trout/mortality" as the "receptor/outcome" combination for which risk will be quantified in this hypothetical case.

\subsection{Step 2a: exposure assessment}

The objective of the Exposure Assessment step in the QRA-SynBio method is to determine the extent of a receptor's exposure in terms of number of SynBio organisms encountered. In this hypothetical case, the assessor defines the scenario of interest as the SynBio product being released to the environment when the decontaminated soil which has been incompletely sterilized after ex situ bioremediation is returned to the excavation site. The SynBio product then transports via groundwater flow to a nearby pond inhabited by Rainbow Trout where it proceeds to infect the trout as they swim through (referred to here as a "swim-through") the contaminated water.

To quantify the receptor's exposure to the SynBio product, the assessor identifies the relevant exposure parameters and their associated data (hypothetical) listed in Table 3 and develops the equation for dose shown in Eq. (1). Because the risk assessor has limited empirical exposure data for the SynBio product, they must rely on surrogate data to populate many of the exposure parameters. The assessor represents many of the exposure parameters as distributions in order to properly account for uncertainty and variability in parameter values.

Equation for daily dose (CFU/day) of SynBio product encountered by a Rainbow Trout once the SynBio product has reached the lake.

Dose $=\mathrm{I} \times \frac{1}{10^{\mathrm{z}}} \times(1+\mathrm{a})^{\mathrm{g} \times \mathrm{t}} \times \frac{1}{\mathrm{P}} \times \mathrm{s} \times \mathrm{q} \times \mathrm{u}$

where,

Dose $=$ Number of CFUs of SynBio product taken up by a Rainbow Trout each day after the SynBio product has reached the lake.

$I=$ Initial remediation inoculum (CFU per $\mathrm{cm}^{3}$ ).

$z=$ Sterilization efficiency $\left(\log _{10}\right.$ reduction per treatment).

$a=$ Asexual inheritance rate of the synthetic construct (unitless).

$g=$ SynBio product growth rate (generations per day).

$t=$ Environmental travel time to lake (days).

$P=$ Soil-water partition coefficient (CFU per $\mathrm{cm}^{3}$ soil/CFU per $\mathrm{cm}^{3}$ water).

$s=$ SynBio product encounter rate for Rainbow Trout ("Swimthroughs" per day).

$q=$ SynBio product intake rate for Rainbow Trout $\left(\mathrm{cm}^{3}\right.$ of water per "swim-through").

Table 3

Mock data for Step 2a: exposure assessment.

\begin{tabular}{|c|c|c|c|}
\hline Parameter & Unit & $\begin{array}{l}\text { Hypothetical } \\
\text { value/Range }\end{array}$ & Distribution \\
\hline Initial remediation inoculum & $\mathrm{CFU}^{\mathrm{a}} / \mathrm{cm}^{3}$ & $10^{9}$ & Point \\
\hline Biocontainment (extrinsic) - sterilization efficiency & $\log _{10}$ reduction per treatment & $8.0-9.0$ & Uniform $($ Min $=8.0 ;$ Max $=9.0)$ \\
\hline Growth rate/die-off rate & Generations/Day (doubling time) & $1.0 \pm 0.1$ & Normal $($ Mean $=1.0 ;$ Std. Dev. $=0.05)$ \\
\hline Environmental travel time to lake & Days & $8.0-9.0$ & Uniform $($ Min $=8.0 ;$ Max $=9.0)$ \\
\hline Asexual inheritance rate of synthetic construct & Unitless & 1.0 & Point \\
\hline Partition coefficient (air, soil, water, flora/fauna) & CFU per $\mathrm{cm}^{3}$ soil/CFU per $\mathrm{cm}^{3}$ water & $1000.0-2200.0: 1.0$ & $\begin{array}{l}\text { Beta }(\operatorname{Min}=1000.0 ; \text { Max }=2200.0 ; \text { Alpha }=1.5 \\
\text { Beta }=4.0)\end{array}$ \\
\hline Encounter rate of environmental receptor & “Swim-throughs"/day & $1-7$ & Lognormal $($ Mean $=3$; Std. Dev. $=1)$ \\
\hline Intake rate of environmental receptor & $\mathrm{cm}^{3} /$ "Swim-through" & $90.0-110.0$ & Uniform $($ Min $=90.0 ;$ Max $=110.0)$ \\
\hline $\begin{array}{l}\text { Transmission rate (percentage of "swim-throughs" } \\
\text { resulting in uptake) }\end{array}$ & Unitless & 0.1 & Point \\
\hline Biocontainment (intrinsic) - e.g., kill switch & $\log _{10}$ reduction per day & 0 & Point \\
\hline $\begin{array}{l}\text { Rate of gene transfer (transformation, conjugation, } \\
\text { transduction) }\end{array}$ & Transfers/day & 0 & Point \\
\hline
\end{tabular}

a $\mathrm{CFU}=$ Colony Forming Units. 
Table 4

Mock data for Step 2b: dose-response assessment.

\begin{tabular}{|c|c|c|c|}
\hline Best-fit model & Equation & $k$ (best-fit value) & $k$ (distribution) \\
\hline Exponential & $P=1-\exp (-k * \mathrm{~d})$ & $6.93 \mathrm{E}-03$ & Lognormal $($ Location $=1.46 \mathrm{E}-03 ;$ Mean $=8.15 \mathrm{E}-03 ;$ Std. Dev. $=4.33 \mathrm{E}-03)$ \\
\hline
\end{tabular}

Where, $P=$ probability of mortality, $d=$ average exposure dose, and $k=$ dose-response parameter specific to the hypothetical SynBio product.

$u=$ Transmission rate (percentage of "swim-throughs" resulting in uptake of SynBio product; unitless.

The assessor also documents the following assumptions that were made when developing the exposure model:

- Escape of the SynBio product from the contained treatment facility is only via material returned to the site; there is no escape to the area of concern via:

o Attachment and subsequent shedding from worker clothing/body

o Treatment facility waste stream (solid, liquid, air)

o Transported material

o Ambient air as aerosol

- There is no intrinsic biocontainment mechanism contributing to dieoff.

- The SynBio product has a $100 \%$ asexual inheritance rate of the synthetic genetic construct; all subsequent generations retain the genetic construct and there is no reversion to wild-type during multiplication in the host.

- There is no horizontal gene transfer of virulence factors from the SynBio product to native organisms so no native organisms become infective to the Rainbow Trout.

- The SynBio product in the returned soil control volume is planktonic and transports via a plug-flow manner (no plume, no loss to soil surface, no partition to air) in the direction of groundwater flow.

- Concentration of SynBio product is uniform (complete mixing) in all control volumes (soil and water)

- The SynBio product's die-off rate in water is proportional to its growth rate in soil such that the soil-growth-partition-to-water-death-inwater cycle maintains a steady-state concentration.

\subsection{Step 2b: dose-response assessment}

The objective of the Dose-response Assessment step in the QRASynBio method is to characterize the relationship between the number of SynBio organisms encountered and the occurrence of the adverse environmental health outcome. The assessor in this case does not have real-world dose-response data for the SynBio product and instead uses surrogate data from a study in which Rainbow Trout were dosed with wild-type $P$. putida $S$-313. The assessor then determines that the endpoint effect requires multiplication in the host and that the best-fit equation in this hypothetical example is the exponential model. The mock data statistics for the best-fit parameter are shown in Table 4.

\subsection{Step 2c: SynBio modifying factors assessment}

The objective of the SynBio Modifying Factors Assessment step in the QRA-SynBio method is to identify the risk factors that impact a SynBio organism's hazard and exposure parameters in the scenario of interest and quantify their impact. The risk assessor in this hypothetical example examines the SynBio product's response to the genetic construct, the gene editing process, and the environmental stressors in the scenario of interest. The assessor determines how these risk factors either increase or decrease the hazard and exposure parameters in the risk quantification.

The assessor finds evidence that three of the exposure parameters must be adjusted to account for expected differences between the SynBio product and the wild-type surrogate data resulting from the SynBio modifying factors (Fig. 3, Table 5).

Modifying these three exposure parameters results in a net decrease in the dose distribution (Fig. 4). Oracle Crystal Ball 11.1.2.4.850 (interfaced with Microsoft Excel 2010) was used to perform the Monte Carlo simulation (10,000 trials) and the best-fit distribution for dose according to Anderson-Darling statistics was determined to be the lognormal distribution (Location $=0.1$; Mean $=3.0$; Std. Dev. $=$ 2.9). The assessor in this hypothetical example used this distribution in Step 3: Risk Characterization.

The assessor also finds evidence that the hypothetical SynBio product is less pathogenic to the Rainbow Trout than wild-type P. putida $S$ 313 and adjusts the distribution for the dose-response parameter $(k)$ based on the evidence (Fig. 5, Table 6). The assessor in this hypothetical example used the adjusted distribution in Step 3: Risk Characterization.

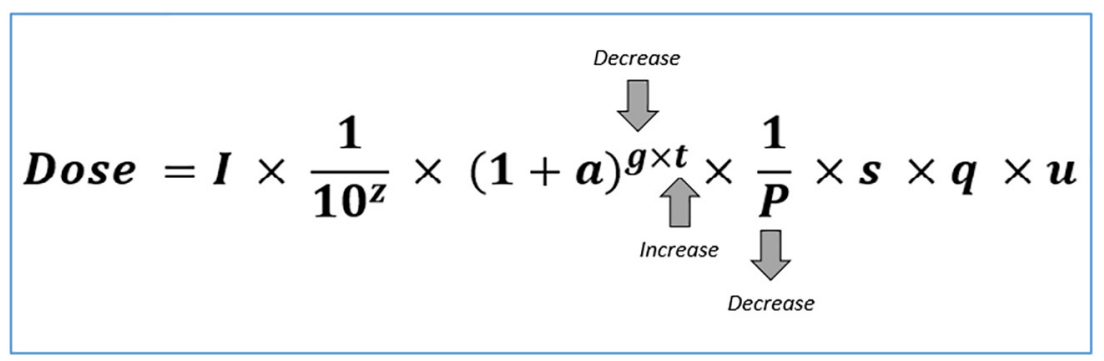

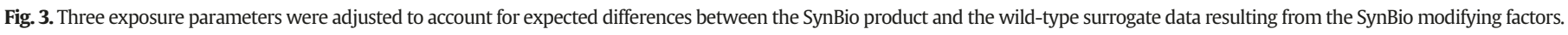

Table 5

Mock exposure data for Step 2c: SynBio modifying factors assessment. SynBio modifying factors result in three adjusted exposure parameters.

\begin{tabular}{|c|c|c|c|}
\hline Parameter & Modification & Modified value/Range & Modified distribution \\
\hline Growth rate/die-off rate & Decrease & $0.5 \pm 0.05$ & Normal $($ Mean $=0.5 ;$ Std. Dev. $=0.025)$ \\
\hline Environmental travel time to lake & Increase & $9.0-10.0$ & Uniform $($ Min $=9.0 ;$ Max $=10.0)$ \\
\hline Partition coefficient (air, soil, water, flora/fauna) & Decrease & 800.0-2000.0:1 & Beta $(\operatorname{Min}=800.0 ; \operatorname{Max}=2000.0 ;$ Alpha $=1.5 ;$ Beta $=4.0)$ \\
\hline
\end{tabular}




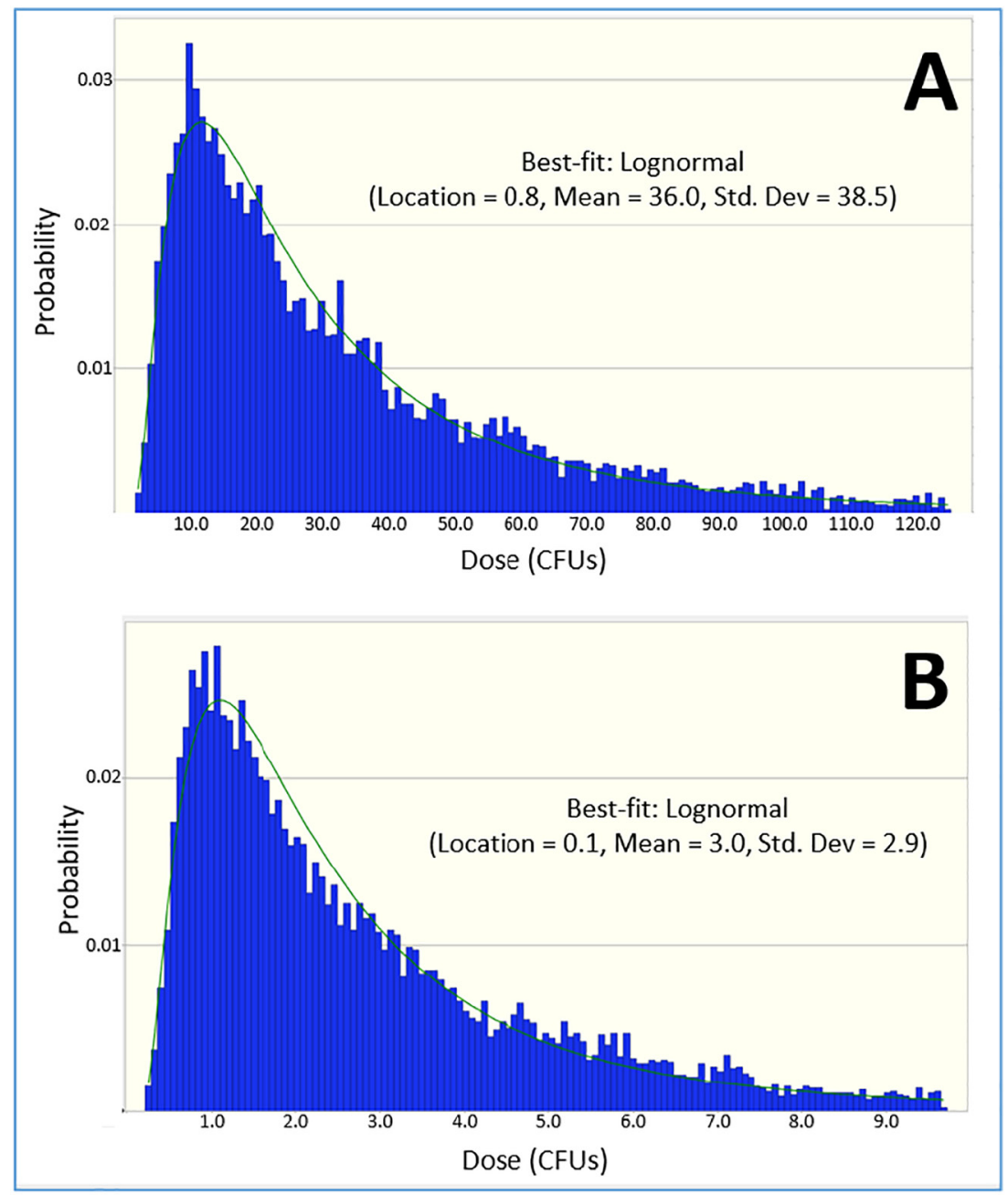

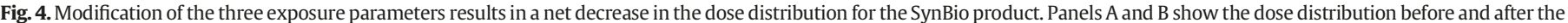
SynBio modifying factors are applied, respectively.

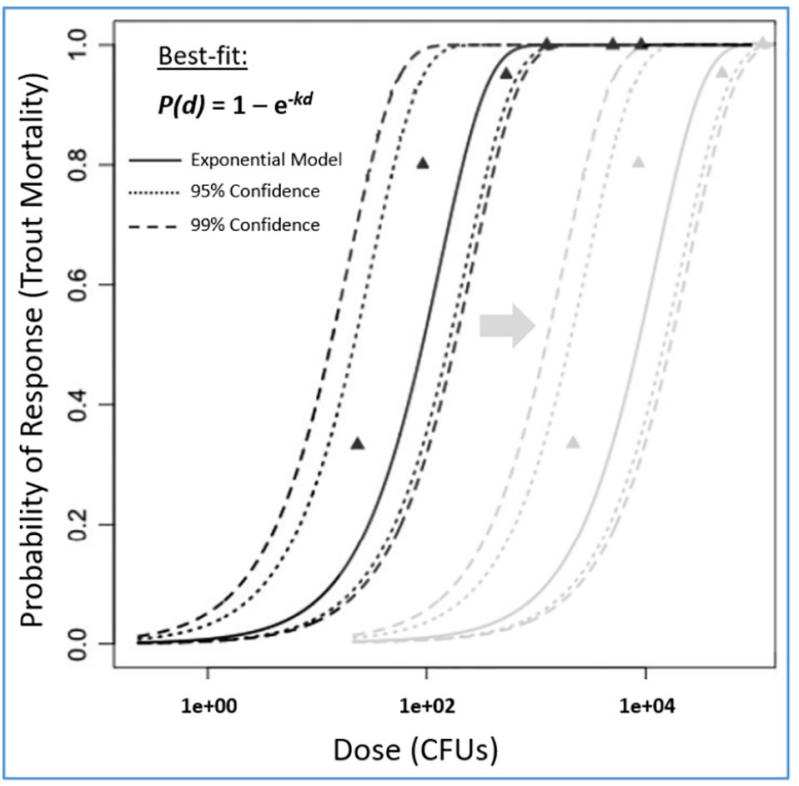

Fig. 5. The dose-response data and resulting curve were adjusted to account for expected differences between the SynBio product and the wild-type surrogate data resulting from the SynBio modifying factors. Uncertainty is determined through bootstrapping.

\subsection{Step 3: risk characterization}

The objective of the Risk Characterization in the QRA-SynBio method is to estimate the magnitude, variability, and uncertainty of the risk of the adverse environmental health outcome in the exposed area. In this example, the assessor performs a Monte Carlo assessment combining the results from the exposure assessment and dose-response assessment into the exponential model to quantify risk of Rainbow Trout mortality. The risk statistics and uncertainty are shown in Table 7, which also illustrates that by incorporating the SynBio modifying factors, the assessor in this hypothetical scenario derived a reduced risk characterization.

The assessor also performs a sensitivity analysis which reveals that the sterilization efficiency $(z)$, SynBio product encounter rate for Rainbow Trout $(s)$, and the dose-response parameter specific to the hypothetical SynBio product $(k)$ contribute most to variability in risk outcome, with $66.5 \%, 12.7 \%$, and $11.2 \%$ of the output variability being attributed to these three inputs, respectively. This result suggests that focusing further data gathering efforts to reduce uncertainty for these three input parameters will have the greatest impact on improving the precision of the forecasted risk of Rainbow Trout mortality.

The QRA-SynBio method illustrated above for P. putida S-313 can be applied to any SynBio product with its own unique risk parameters and parameter values. These SynBio products can span eukarya, bacteria, and archaea domains and can include single-cellular and multicellular organisms as well as viruses and cell-free materials. 
Table 6

Mock dose-response data for Step 2c: SynBio modifying factors assessment. SynBio modifying factors result in an adjusted dose-response parameter ( $k$ ).

\begin{tabular}{|c|c|c|c|}
\hline Parameter & Modification & Modified value/Range & Modified distribution \\
\hline Dose-response parameter $(k)$ & Decrease & $6.93 \mathrm{E}-05$ & Lognormal $($ Location $=1.90 \mathrm{E}-05 ;$ Mean $=8.10 \mathrm{E}-05 ;$ Std. Dev. $=2.50 \mathrm{E}-05)$ \\
\hline
\end{tabular}

\section{Conclusion}

As demonstrated above, the QRA-SynBio method is an incremental build on established risk assessment paradigms. It utilizes the traditional Hazard Identification, Exposure Assessment, Dose-Response Assessment, and Risk Characterization steps, and adds the SynBio Modifying Factors Assessment to account for SynBio-specific risk factors. The objective of this proposed method is to move the SynBio risk assessment field beyond high-level, qualitative discussions of biosafety and biosecurity and promote detailed, quantitative characterizations of the environmental risks of SynBio products that acknowledge and incorporate the factors that make SynBio products unique.

A key challenge for the QRA-SynBio method is that it relies on quantitative data for the SynBio modifying factors which, at present, are limited and highly uncertain. More empirical data are needed to quantify the differences in risk parameters between SynBio products and wildtype surrogates, inform the magnitude of parameter adjustments, and support assumptions made during the risk assessment. Moe-Behrens et al. emphasize that determining the behavior of a SynBio product in relevant microcosms is essential, and that scientists are perfectly capable of measuring differences between synthetic versus wild type organisms (Moe-Behrens et al., 2013). Ideally such microcosm studies would be conducted for all hazard and exposure parameters in a risk scenario, but the priority should be to conduct them for the most impactful parameters as identified by sensitivity analysis. The QRA-SynBio method can quantify the sensitivity of risk parameters, thereby helping to direct experimental investigation toward data gaps and parameters where uncertainty should be reduced. The QRA-SynBio method can also be used to address data gaps by "reverse QRA" in which an assessor specifies a risk level and back-calculates the magnitude of modifying factors required to yield that risk level (e.g., how many off target gene edits yield a $10 \%$ adverse response).

The concept of a quantitative risk assessment framework that accurately captures the novel properties of SynBio products was discussed in a March 2018 workshop hosted by the US Army Engineer Research and Development Center's Environmental Laboratory which included SynBio technical experts, regulators, risk assessors, and community engagement experts (Trump et al., 2018). Participants emphasized the immediate need for benchmarking studies that show relative differences between synthetic and wild-type behaviors as well as adapted protocols for identifying potential adverse environmental health outcomes. Participants also identified a need to develop a method for prioritizing receptor/adverse health endpoint combinations (e.g., Rainbow Trout/ mortality) for risk quantification, and recommended that the public and other potentially affected stakeholders should have input into which receptor/endpoint pairings are relevant. It was suggested that such stakeholder participation may lead to increased trust in the conclusions of a risk assessment and may, in turn, foster broader acceptance of

Table 7

Summary of descriptive statistics of $\log _{10}$ risk (10,000 trials) of Rainbow Trout mortality per daily exposure once the SynBio product has reached the lake.

\begin{tabular}{lcc}
\hline & $\begin{array}{c}\log _{10} \text { mortality risk: before } \\
\text { applying modifying factors }\end{array}$ & $\begin{array}{l}\log _{10} \text { mortality risk: after } \\
\text { applying modifying factors }\end{array}$ \\
\hline Minimum & -2.20 & -4.93 \\
1st Quartile & -1.06 & -4.03 \\
Median & -0.79 & -3.78 \\
Mean & -0.66 & -3.62 \\
3rd Quartile & -0.54 & -3.53 \\
Maximum & 0.00 & -2.14 \\
\hline
\end{tabular}

SynBio technologies. The workshop participants also emphasized that any risk assessment framework proposed specifically for SynBio products must be flexible because it may require frequent adaptation as the discipline continues to advance at such a rapid pace.

The QRA-SynBio method described and demonstrated here is flexible, objective, and transparent, and can accommodate all SynBio products as potential ecological hazards and any environmental receptor and health endpoint. It is also an incremental build on previous risk assessment approaches rather than a dramatic shift that eschews preexisting methods, an attribute which increases its potential for adoption by regulatory agencies because of the institutional difficulty those agencies face in crafting and implementing any new oversight or risk assessment mechanisms. Refinement will be necessary as the framework is applied to a variety of SynBio products, but the QRA-SynBio method has the potential to be the standard risk assessment framework that the synthetic biology discipline is currently missing.

\section{Acknowledgements}

This work was funded in part by the U.S. Army Environmental Quality and Installations Research Program (Dr. Elizabeth Ferguson was the technical director). The findings and conclusions in this report are those of the authors and do not necessarily represent the official position of the U.S. Army Engineer Research and Development Center.

\section{References}

Ahteensuu, M., 2017. Synthetic biology, genome editing, and the risk of bioterrorism. Sci. Eng. Ethics 23 (6), 1541-1561.

Altinok, I., Kayis, S., Capkin, E., 2006. Pseudomonas putida infection in rainbow trout Aquaculture 261 (3), 850-855.

Bates, M.E., Grieger, K.D., Trump, B.D., Keisler, J.M., Plourde, K.J., Linkov, I., 2015. Emerging technologies for environmental remediation: integrating data and judgment. Environmental science \& technology 50 (1), 349-358.

Birchler, J.A., 2015. Promises and pitfalls of synthetic chromosomes in plants. Trends Biotechnol. 33 (3), 189-194.

Breckling, B., Schmidt, G., 2015. Synthetic biology and genetic engineering: parallels in risk assessment. Synthetic Biology. Springer, Cham, pp. 197-211.

Cai, Y., Agmon, N., Choi, W.J., Ubide, A., Stracquadanio, G., Caravelli, K., Hao, H., Bader, J.S Boeke, J.D., 2015. Intrinsic biocontainment: multiplex genome safeguards combine transcriptional and recombinational control of essential yeast genes. Proc. Natl Acad. Sci. 112 (6), 1803-1808.

Cases, I., de Lorenzo, V., 2005. Genetically modified organisms for the environment: stories of success and failure and what we have learned from them. Int. Microbiol. 8 (3), 213-222.

Center for Advancing Microbial Risk Assessment (CAMRA), 2018. Quantitative microbial risk assessment. Available at. http://www.camra.msu.edu/qmra.html, Accessed date: 4 April 2018.

Chan, C.T., Lee, J.W., Cameron, D.E., Bashor, C.J., Collins, J.J., 2016. 'Deadman' and 'Passcode' microbial kill switches for bacterial containment. Nat. Chem. Biol. 12 (2), 82.

Chen, B.S., Chang, C.H., Lee, H.C., 2009. Robust synthetic biology design: stochastic game theory approach. Bioinformatics 25 (14), 1822-1830.

Cocolin, L., Mataragas, M., Bourdichon, F., Doulgeraki, A., Pilet, M.F., Jagadeesan, B., Rantsiou, K., Phister, T., 2018. Next generation microbiological risk assessment meta-omics: the next need for integration. Int. J. Food Microbiol. 287, 10-17.

Crisp, A., Boschetti, C., Perry, M., Tunnacliffe, A., Micklem, G., 2015. Expression of multiple horizontally acquired genes is a hallmark of both vertebrate and invertebrate genomes. Genome Biol. 16 (1), 50.

Dagan, T., Artzy-Randrup, Y., Martin, W., 2008. Modular networks and cumulative impact of lateral transfer in prokaryote genome evolution. Proc. Natl. Acad. Sci. 105 (29), 10039-10044

Dagan, T., Roettger, M., Stucken, K., Landan, G., Koch, R., Major, P., Gould, S.B., Goremykin, V.V., Rippka, R., Tandeau de Marsac, N., Gugger, M., 2012. Genomes of Stigonematalean cyanobacteria (subsection $\mathrm{V}$ ) and the evolution of oxygenic photosynthesis from prokaryotes to plastids. Genome biology and evolution 5 (1), 31-44.

Dan-Cohen, T., 2016. Ignoring complexity: epistemic wagers and knowledge practices among synthetic biologists. Sci. Technol. Hum. Values 41 (5), 899-921.

van Doren, D., Heyen, N.B., 2014. Synthetic biology: too early for assessments? A review of synthetic biology assessments in Germany. Sci. Public Policy 41 (3), 272-282. 
Edwards, B., 2014. Taking stock of security concerns related to synthetic biology in an age of responsible innovation. Front. Public Health 2, 79 .

Epstein, M.M., Vermeire, T., 2016. Scientific opinion on risk assessment of synthetic biology. Trends Biotechnol. 34 (8), 601-603.

EU Commission, 2001. Directive 2001/18/EC of the European Parliament and of the Council of 12 March 2001 on the Deliberate Release into the Environment of Genetically Modified Organisms and Repealing Council Directive 90/220. EEC.

EU Commission (EC): Opinion on Synthetic Biology II: Risk Assessment Methodologies and Safety Aspects. European Union. European Commission Scientific Committees, May, 2015. Available at http://ec.europa.eu/health/scientific_committees/emerging/ docs/scenihr_o_048.pdf (accessed April 4, 2018).

Falkow, S., 2012. The lessons of Asilomar and the H5N1 "affair". MBio, 3(5), pp. e00354-12.

Fowle, J.R., Dearfield, K.L., 2000. Risk Characterization Handbook. Science Policy Council, US Environmental Protection Agency.

Frank, D., Heil, R., Coenen, C., König, H., 2015. Synthetic biology's self-fulfilling prophecydangers of confinement from within and outside. Biotechnol. J. 10 (2), 231-235.

Fu, Y., Foden, J.A., Khayter, C., Maeder, M.L., Reyon, D., Joung, J.K., Sander, J.D., 2013. Highfrequency off-target mutagenesis induced by CRISPR-Cas nucleases in human cells. Nat. Biotechnol. 31 (9), 822.

Furumoto, W.A., Mickey, R., 1967a. A mathematical model for the infectivity-dilution curve of tobacco mosaic virus: experimental tests. Virology 32 (2), 224-233.

Furumoto, W.A., Mickey, R., 1967b. A mathematical model for the infectivity-dilution curve of tobacco mosaic virus: theoretical considerations. Virology 32 (2), 216-223.

Gallagher, R.R., Patel, J.R., Interiano, A.L., Rovner, A.J., Isaacs, F.J., 2015. Multilayered genetic safeguards limit growth of microorganisms to defined environments. Nucleic Acids Res. 43 (3), 1945-1954.

Giese, B., von Gleich, A., 2015. Hazards, risks, and low hazard development paths of synthetic biology. Synthetic Biology. Springer, Cham, pp. 173-195.

Haas, C.N., 1996. How to average microbial densities to characterize risk. Water Res. 30 (4), 1036-1038.

Haas, C.N., 2015. Microbial dose response modeling: past, present, and future. Environmental Science \& Technology 49 (3), 1245-1259.

Haas, C.N., Rose, J.B., Gerba, C.P., 2014. Quantitative Microbial Risk Assessment. 2nd ed. John Wiley \& Sons, Hoboken, New Jersey.

Hamilton, K.A., Weir, M.H., Haas, C.N., 2017. Dose response models and a quantitative microbial risk assessment framework for the Mycobacterium avium complex that account for recent developments in molecular biology, taxonomy, and epidemiology. Water Res. 109, 310-326.

Howard, J., Murashov, V., Schulte, P., 2017. Synthetic biology and occupational risk. J. Occup. Environ. Hyg. 14 (3), 224-236.

Hruscha, A., Krawitz, P., Rechenberg, A., Heinrich, V., Hecht, J., Haass, C., Schmid, B., 2013. Efficient CRISPR/Cas9 genome editing with low off-target effects in zebrafish. Development 140 (24), 4982-4987.

Jackson, R.J., Ramsay, A.J., Christensen, C.D., Beaton, S., Hall, D.F., Ramshaw, I.A., 2001. Expression of mouse interleukin- 4 by a recombinant ectromelia virus suppresses cytolytic lymphocyte responses and overcomes genetic resistance to mousepox. J. Virol. 75 (3), 1205-1210.

Kim, D., Bae, S., Park, J., Kim, E., Kim, S., Yu, H.R., Hwang, J., Kim, J.I., Kim, J.S., 2015. Digenome-seq: genome-wide profiling of CRISPR-Cas9 off-target effects in human cells. Nat. Methods 12 (3), 237.

König, H., Frank, D., Heil, R., Coenen, C., 2013. Synthetic genomics and synthetic biology applications between hopes and concerns. Current Genomics 14 (1), 11-24.

König, H., Frank, D., Heil, R., Coenen, C., 2016. Synthetic biology's multiple dimensions of benefits and risks: implications for governance and policies. Synthetic Biology. Springer VS, Wiesbaden, pp. 217-232.

McDaniel, L.D., Young, E., Delaney, J., Ruhnau, F., Ritchie, K.B., Paul, J.H., 2010. High frequency of horizontal gene transfer in the oceans. Science 330 (6000), 50.

Moe-Behrens, G.H., Davis, R., Haynes, K.A., 2013. Preparing synthetic biology for the world. Front. Microbiol. 4, 5.

National Academies of Sciences, Engineering, and Medicine, 2017. Preparing for Future Products of Biotechnology. The National Academies Press, Washington, DC https:// doi.org/10.17226/24605.

National Institutes of Health (NIH), 2016. NIH Guidelines for Research Involving Recombinant or Synthetic Nucleic Acid Molecules. U.S. Department of Health and Human Services Available at. https://osp.od.nih.gov/wp-content/uploads/2013/06/NIH Guidelines.pdf, Accessed date: 4 April 2018.
National Research Council (NRC), 1983. Risk Assessment in the Federal Government: Managing the Process. National Academies Press.

National Research Council (NRC), 2002. Animal Biotechnology: Science Based Concerns. National Academies Press.

Neilson, J.W., Josephson, K.L., Pepper, I.L., Arnold, R.B., Di Giovanni, G.D., Sinclair, N.A., 1994. Frequency of horizontal gene transfer of a large catabolic plasmid (pJP4) in soil. Appl. Environ. Microbiol. 60 (11), 4053-4058.

Norton, S.B., Rodier, D.J., van der Schalie, W.H., Wood, W.P., Slimak, M.W., Gentile, J.H., 1992. A framework for ecological risk assessment at the EPA. Environ. Toxicol. Chem. 11 (12), 1663-1672.

Ochman, H., Lawrence, J.G., Groisman, E.A., 2000. Lateral gene transfer and the nature of bacterial innovation. Nature 405 (6784), 299.

Pósfai, G., Plunkett, G., Fehér, T., Frisch, D., Keil, G.M., Umenhoffer, K., Kolisnychenko, V., Stahl, B., Sharma, S.S., De Arruda, M., Burland, V., 2006. Emergent properties of reduced-genome Escherichia coli. Science 312 (5776), 1044-1046.

Ravikumar, A., Liu, C.C., 2015. Biocontainment through reengineered genetic codes. ChemBioChem 16 (8), 1149-1151.

Sayler, G.S., Ripp, S., 2000. Field applications of genetically engineered microorganisms for bioremediation processes. Curr. Opin. Biotechnol. 11 (3), 286-289.

SCENIHR, SCHER, and SCCS, 2015. Synthetic Biology III-Risks to the Environment and Biodiversity Related to Synthetic Biology and Research Priorities in the Field of Synthetic Biology, Opinion, December 2015. SCENIHR, SCHER, and SCCS.

Schmidt, M., Pei, L., 2015. Improving biocontainment with synthetic biology: Beyond physical containment. Hydrocarbon and Lipid Microbiology Protocols. Springer, Berlin, Heidelberg, pp. 185-199.

Schmidt, M., Kelle, A., Ganguli-Mitra, A., de Vriend, H. (Eds.), 2009. Synthetic Biology: The Technoscience and its Societal Consequences. Springer Science \& Business Media.

Schwartz, J.A., Curtis, N.E., Pierce, S.K., 2014. FISH labeling reveals a horizontally transferred algal (Vaucheria litorea) nuclear gene on a sea slug (Elysia chlorotica) chromosome. Biol. Bull. 227 (3), 300-312.

Torres, L., Krüger, A., Csibra, E., Gianni, E., Pinheiro, V.B., 2016. Synthetic biology approaches to biological containment: pre-emptively tackling potential risks. Essays Biochem. 60 (4), 393-410.

Trump, B.D., Foran, C., Rycroft, T., Wood, M.D., Bandolin, N., Cains, M., Cary, T., Crocker, F., Friedenberg, N.A., Gurian, P., Hamilton, K., 2018. Development of community of practice to support quantitative risk assessment for synthetic biology products: contaminant bioremediation and invasive carp control as cases. Environment Systems and Decisions 38 (4), 517-527.

Trump, B.D., Cegan, J., Wells, E., Poinsatte-Jones, K., Rycroft, T., Warner, C., Martin, D., Perkins, E.J. Wood, M.D., Linkov, I., 2019. Co-evolution of physical and social sciences in synthetic biology. Crit. Rev. Biotechnol. 39 (3), 351-365.

Tucker, J.B., Zilinskas, R.A., 2006. The promise and perils of synthetic biology. The New Atlantis 12, 25-45.

U.S. Environmental Protection Agency (EPA), 2018. Conducting a Human Health Risk Assessment. Available at. https://www.epa.gov/risk/conducting-human-health-risk-assessment, Accessed date: 4 April 2018.

U.S. Food and Drug Administration, 2015. AquAdvantage Salmon Environmental Assessment. Available at. https://www.fda.gov/AnimalVeterinary/DevelopmentApproval Process/GeneticEngineering/GeneticallyEngineeredAnimals/ucm280853.htm, Accessed date: 4 April 2018

U.S. Food and Drug Administration, 2016. Environmental Assessment for Investigational Use of Aedes aegypti OX513A. Available at. https://www.fda.gov/AnimalVeterinary/ NewsEvents/CVMUpdates/ucm490246.htm, Accessed date: 4 April 2018.

Vos, M., Hesselman, M.C., te Beek, T.A., van Passel, M.W., Eyre-Walker, A., 2015. Rates of lateral gene transfer in prokaryotes: high but why? Trends Microbiol. 23 (10), 598-605.

Warner, C.M. Carter, S.R., Lance, R.F., Crocker, F.H., Meeks, H.N., Adams, B.L, Magnuson, M.L., Rycroft, T., Pokrzywinski, K. and Perkins, E.J., 2019. Synthetic Biology: Research Needs for Assessing Environmental Impacts. ERDC/EL TR-19-10. Available at: doi: 10.21079/11681/33681 (accessed August 13, 2019).

Zamani-Dahaj, S.A., Okasha, M., Kosakowski, J., Higgs, P.G., 2016. Estimating the frequency of horizontal gene transfer using phylogenetic models of gene gain and loss. Mol. Biol. Evol. 33 (7), 1843-1857.

Zhang, X.H., Tee, L.Y., Wang, X.G., Huang, Q.S., Yang, S.H., 2015. Off-target effects in CRISPR/Cas9-mediated genome engineering. Molecular Therapy-Nucleic Acids 4. 


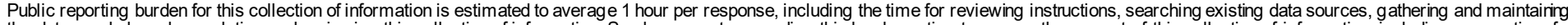

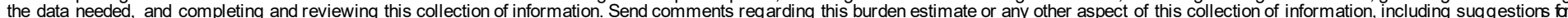

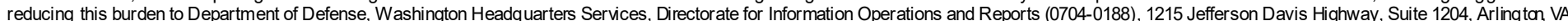

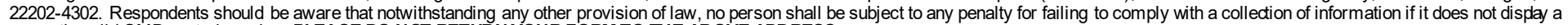
22202-4302. Respondents should be aware that notwithstanding any other provision of law, no person shall be
currently valid OMB control number. PLEASE DO NOT RETURN YOUR FORM TO THE ABOVE ADDRESS.
1. REPORT DATE (DD-MM-YYYY) 2. REPORT TYPE July 2021 Final

3. DATES COVERED (From - To)

4. TITLE AND SUBTITLE

A Quantitative Risk Assessment Method for Synthetic Biology Products in the Environment

\section{5a. CONTRACT NUMBER}

5b. GRANT NUMBER

5c. PROGRAM ELEMENT NUMBER

6. AUTHOR(S)

Taylor Rycroft, Kerry Hamilton, Charles N. Haas, Igor Linkov

5d. PROJECT NUMBER

5e. TASK NUMBER

5f. WORK UNIT NUMBER

7. PERFORMING ORGANIZATION NAME(S) AND ADDRESS(ES)

See next page.

8. PERFORMING ORGANIZATION REPORT
NUMBER

ERDC/EL MP-21-4

9. SPONSORING / MONITORING AGENCY NAME(S) AND ADDRESS(ES)

10. SPONSOR/MONITOR'S ACRONYM(S)

U.S. Army Corps of Engineers

Wa shington, DC 20314

11. SPONSOR/MONITOR'S REPORT NUMBER(S)

\section{DISTRIBUTION / AVAILABILITY STATEMENT}

Approved for public release; distribution is unlimited.

\section{SUPPLEMENTARY NOTES}

This a rticle was originally published online in Science of the Total Environment on 14 August 2019.

This work was funded in part by the U.S. Army Environmental Qua lity and Installa tions Research Program.

\section{ABSTRACT}

The need to prevent possible adverse environmental health impacts resulting from synthetic biology (SynBio) products is widely a cknowledged in both the SynBio risk litera ture and the global regula tory community. However, discussions of potential risks of SynBio products have been largely speculative, and the a ttempts to characterize therisks of SynBio products have been non-uniform and entirely qualitative. As the discipline continues to accelerate, a standardized risk a ssessment framework will become critical for ensuring that the environmental risks of these products a recharacterized in a consistent, reliable, and objective manner that incorporates all SynBio-uniquerisk factors. Current established risk assessment frameworks fall short of the features required of this sta ndard framework. To a ddress this, we propose the Quantitative Risk Assessment Method for Synthetic Biology Products (QRASynBio) - an incremental build on established risk assessment methodo logies that supplements traditional paradigms with the SynBio risk factors that are currently absent and necessitates quantitative a naly sis for more transparent and objective risk characterizations. The proposed framework facilita tes defensible quantification of the environmental risks of SynBio products in both foreseeable and hypothetical use scenarios. Additionally, we show how the proposed method can promote increased experimental investigation into the likelihood of hazard and exposure parameters and high light the parameters where uncertainty should be reduced, lea ding to more ta rgeted risk research and more precise characterizations of risk.

\section{SUBJECT TERMS}

Synthetic biology, Risk assessment, Environmentalhealth and safety

\begin{tabular}{|c|c|c|c|c|c|}
\hline \multicolumn{3}{|c|}{ 16. SECURITY CLASSIFICATION OF: } & \multirow{2}{*}{$\begin{array}{l}\text { 17. LIMITATION } \\
\text { OF ABSTRACT } \\
\text { UU }\end{array}$} & \multirow{2}{*}{$\begin{array}{c}\text { 18. NUMBER } \\
\text { OF PAGES } \\
19\end{array}$} & \multirow{2}{*}{$\begin{array}{l}\text { 19a. NAME OF RESPONSIBLE } \\
\text { PERSON } \\
\begin{array}{l}\text { 19b. TELEPHONE NUMBER (include } \\
\text { area code) }\end{array}\end{array}$} \\
\hline $\begin{array}{l}\text { a. REPORT } \\
\text { Unclassified }\end{array}$ & $\begin{array}{l}\text { b. ABSTRACT } \\
\text { Unclassified }\end{array}$ & $\begin{array}{l}\text { c. THIS PAGE } \\
\text { Unclassified }\end{array}$ & & & \\
\hline
\end{tabular}


7. PERFORMING ORGANIZATION NAME(S) AND ADDRESS(ES)

Environmental Laboratory

U.S. Army Engineer Research and Development Center 3909 Halls Ferry Road

Vicksburg, MS 39180

School for Sustainable Engineering and the Built Environment

The Biodesign Institute Center for Environmental Health Engineering, Arizona State University

Tempe, AZ 85281

Department of Civil, Architectural and Environmental Engineering Drexel University

Philadelphia, PA 19104 